\title{
Erro e correção: as crenças de dois professores de escola pública e de alguns de seus alunos
}

\author{
Suelene Vaz da Silva \\ Universidade Estadual de Goiás - UEG \\ Francisco José Quaresma de Figueiredo \\ Universidade Federal de Goiás - UFG
}

Este estudo aborda a temática crenças, especificamente as crenças de professores e alunos de LE (inglês) da rede pública de ensino a respeito da correção de erros. A investigação, de cunho qualitativo, foi conduzida em uma cidade próxima a Goiânia, capital do Estado de Goiás, e buscou estabelecer relações entre as crenças dos professores e as crenças de alguns de seus alunos dos Ensinos Fundamental e Médio, no segundo semestre de 2003. Os dados foram coletados por meio de questionários, entrevistas, notas de campo, observações e filmagens de aulas e analisados sob duas perspectivas: estudos sobre crenças relacionadas ao processo de ensino e aprendizagem de Horwitz (1985, 1988, 1999), Pajares (1992), Johnson (1994, 1999), Barcelos (1995, 1999, 2004a, 2004b) entre outros, e estudos sobre erro e correção de Schulz (1996), Figueiredo (1997, 2005), Lee (2003), entre outros. Os resultados apontam que as experiências que os professores tiveram, quando eram aprendizes de LE, influenciam sua prática cotidiana em sala de aula, bem como as formas como lidam com as questões relativas a erro e correção. Tais crenças são compartilhadas por alguns dos alunos, mas conflitantes com as de outros. Conclui-se, portanto, que é importante fornecer subsídios para que os professores possam conhecer, refletir, discutir e questionar suas crenças, de forma geral, e não apenas sobre erro e correção.

This study has as its focus the beliefs which affect both FL teachers and students in regard to error correction. Its main objective was to infer and analyze beliefs related to error correction held by two public school teachers of English in a town next to Goiânia, the capital of the State of Goiás. The investigation also tried to establish relations between the teachers' beliefs and the beliefs of some of their pupils. Adopting a qualitative perspective in the data collection and analysis, this case study was conducted in the second semester of 2003. The data were collected by means of questionnaires, interviews, field notes, class observations and video-recordings, which were analyzed in the light of studies on beliefs related to the teaching-learning process by Horwitz (1985, 1988, 1999), Pajares (1992), Johnson (1994, 1999), Barcelos (1995, 1999, 2004a, 2004b), among others, and investigations on error and correction by Schulz (1996), Figueiredo (1997, 2005), Lee (2003), among others. Amongst the 


\begin{abstract}
conclusions we arrived at, we observed that the teachers' prior experiences as FL students influence their daily classroom practice, as well as the ways they deal with the issue concerning error correction. Such beliefs are shared by some of the pupils, but conflict with the ones held by others. The results highlight the importance of offering opportunities for teachers to get to know, reflect, argue and question their beliefs in general, and not only about error and correction.
\end{abstract}

\title{
Introdução
}

O construto crenças tem se tornado um importante tópico de investigação, no âmbito educacional, pelo fato de focalizar o modo como os indivíduos constroem suas próprias abordagens em relação ao processo de ensino e aprendizagem. Tal processo, ocorrendo no ambiente formal da sala de aula, é permeado por fatores e atividades de natureza cognitiva e sociocultural.

Como agentes socialmente construídos, tanto os professores quanto os alunos baseiam suas ações e comportamentos nas maneiras pelas quais percebem, entendem e interpretam os eventos ocorridos nesse ambiente, os quais, por sua vez, refletem seus conhecimentos e crenças (ABELSON, 1979; MUNBY, 1984; HORWITZ, 1985, 1988, 1999; NESPOR, 1987; LEFFA, 1991; PAJARES, 1992; PINTRICH, MARX; BOYLE, 1993; JOHNSON, 1994, 1999; BARCELOS, 1995, 1999, 2001, 2004a, 2004b; WOODS, 1996; RICHARDS; LOCKHART, 1996; SILVA, 2000; BARCELOS; VIEIRA ABRAHÃO, 2006, entre outros).

$\mathrm{Na}$ aprendizagem de línguas estrangeiras (LE), o que acreditamos constituir-se ou não um erro está, muitas vezes, relacionado com o nosso próprio modo de agir diante das situações que vivenciamos no nosso cotidiano. Nesse sentido, é importante considerar o fato de que aprendizes e professores são indivíduos que possuem suas formas particulares de pensar e de agir em relação ao que seja erro dentro do processo de ensino e aprendizagem, bem como em relação a por que, como e quando corrigi-lo.

Este estudo tem por objetivo investigar as crenças relacionadas a erro e correção de dois professores de escola pública, compreender de que forma tais crenças influenciam sua prática pedagógica e verificar se as formas de correção empregadas por eles vão ao encontro das expectativas de seus alunos. 


\section{Fundamentação teórica}

Na literatura da área, há um grande número de designações que foram utilizadas para denominar o termo crenças. Essa profusão de definições sobre esse construto, especificamente na área de Lingüística Aplicada, é salientada por Barcelos (2004a) como sendo, ao mesmo tempo, intrincada e importante, porque demonstra tanto as mudanças no paradigma de investigação de crenças quanto um consenso de que "crenças sobre aprendizagem de linguas, obviamente, são crenças a respeito do que é linguagem, do que é aprendizagem de línguas e sobre aspectos pertinentes à linguagem e à aprendizagem, ou toda tarefa de aprender" (BARCELOS, 2004a, p. 132, grifo no original).

Woods (1996) afirma que as crenças são interativas, dinâmicas, sociais e influenciam o comportamento dos aprendizes e o dos professores, bem como são influenciadas no decorrer do processo de ensino e aprendizagem. Dessa forma, Barcelos (2004a) sugere que, para sermos críticos e reflexivos em nossos processos de aprender e ensinar línguas, é importante que alunos e professores em formação conheçam, discutam e questionem não só suas próprias crenças, mas crenças em geral, para que ambos - estudantes e educadores - estejam mais bem preparados para lidar com a diversidade de crenças nas salas de aulas.

Segundo Johnson (1994), apesar de as crenças dos professores representarem influências importantes no modo como eles pensam, compreendem e agem, pouca atenção tem sido dada à natureza das origens dessas crenças e como elas se manifestam na realidade cotidiana profissional do professor.

Segundo Pajares (1992) e Johnson (1999), as crenças dos professores podem ser entendidas como uma subestrutura de crenças que se interrelacionam com todas as outras existentes. Portanto, elas não estão claramente reveladas, e precisam, em alguns casos, ser inferidas pelo pesquisador.

No que concerne à aprendizagem, Horwitz $(1988,1999)$ afirma que o estudo de crenças não tem por objetivo dizer se elas estão certas ou erradas, mas, sim, discutir seu impacto nas expectativas e nas estratégias de aprendizagem dos estudantes. Para essa autora, por meio de pesquisas sobre crenças, uma pessoa pode visualizar muitas instâncias em que noções pré-concebidas sobre aprendizagem de língua provavelmente influenciariam a eficácia do aprendizado em sala de aula. 
Outro ponto importante, levantado por Pintrich, Marx e Boyle (1993) e por Kern (1995), é o fato de que a condução de discussões sobre aprendizagem de línguas entre estudantes e professores pode propiciar uma parceria reflexiva, o que os ajudaria a superar obstáculos à aprendizagem. Para os autores, ao se unirem nessa atividade, esses dois importantes agentes do processo de ensinar e aprender estarão manifestando seus pensamentos e ações de modo colaborativo.

De acordo com Freitas, Belincanta e Corrêa (2002), Frey (2002) e Mateus, Gimenez, Ortenzi e Reis (2002), uma abordagem reflexiva começa a contestar o então divulgado modelo de treinamento. Procura-se entender o que o professor faz em sua prática, como faz e por que faz, a partir de dados reais, e, assim, propiciar-lhe condições para conhecer teorias que possam sustentar ou modificar sua prática cotidiana.

\section{Crenças e correção de erros}

Schulz (1996) realizou um estudo descritivo sobre crenças relacionadas à correção de erros no processo de ensino e aprendizagem, independentemente da língua estrangeira estudada. A investigação teve como participantes 824 aprendizes e 92 professores de LE. Para a realização dessa pesquisa, primeiramente aplicou-se aos alunos um questionário com 12 itens, dos quais 5 se relacionavam diretamente às crenças sobre erro e correção. ${ }^{1}$ Os professores, por sua vez, responderam, por e-mail, a um outro questionário com itens semelhantes ao aplicado para os alunos.

Em relação aos aprendizes dos dois grupos, Schulz (1996) concluiu que a maioria deles acreditava que os professores deviam corrigi-los, em sala de aula, pois eles gostavam de ter seus erros, orais e escritos, corrigidos durante as aulas de LE e que se sentiam enganados quando os professores não corrigiam as atividades escritas que eles entregavam.

\footnotetext{
${ }^{1}$ Os cinco itens são: (1) Eu não gosto quando sou corrigido em sala de aula; (2) Os professores não devem corrigir os alunos quando eles comentem erros durante as aulas; (3) Eu me sinto enganado quando meu professor não corrige as tarefas escritas que eu entrego; (4) Quando eu cometo erro oral na línguaalvo, eu quero que meu professor me corrija; (5) Quando eu cometo erro escrito, eu quero ser corrigido.
} 
Schulz (1996) acrescenta que a análise gramatical e o feedback corretivo são bem-vindos às aulas de LE. Porém, para a aplicação de ambos, é importante que sejam considerados os aspectos específicos de cada língua, as características dos aprendizes (estilo, idade, motivação, aptidão etc.), circunstâncias institucionais, tipo de instrução e como a intervenção será realizada.

Lee (2003) desenvolveu um estudo sobre crenças relacionadas a erro e correção com 206 professores de ensino secundário em Hong Kong. O estudo buscou verificar como os professores corrigiam atividades escritas, como percebiam a ação de corrigir e quais eram as preocupações e os problemas relacionados ao ato de corrigir. A autora observou algumas discrepâncias entre o que os professores acreditavam e o que realmente faziam, como, por exemplo, oferecer feedback seletivo para os erros cometidos pelos alunos, variar nos tipos de feedback e serem os responsáveis pela identificação e correção dos erros dos alunos. Quanto ao papel dos aprendizes, os professores acreditavam que os alunos deviam aprender a identificar, a analisar e a corrigir os próprios erros. Contudo, os professores não ofereciam aos alunos oportunidades para desenvolver tais ações. A autora concluiu que, apesar de os professores sofrerem pressão da instituição, dos pais de alunos e dos próprios alunos para corrigir erros seletivamente, eles preferiam fazer uso da correção direta ${ }^{2}$ por três motivos: ela é a norma praticada nas aulas de composição em Hong Kong; há uma falta de conhecimento por parte deles de outras técnicas de feedback; e há uma ausência de reflexões sobre esse tipo de correção praticada.

No contexto brasileiro, Lyrio (2001) conduziu um estudo em uma universidade pública no Estado do Espírito Santo sobre as expectativas de professores e de alunos relativas à correção oral. Os participantes da pesquisa, 608 alunos e 15 professores, responderam a um questionário com itens semelhantes. Os resultados demonstraram conflitos entre as expectativas dos professores e dos alunos. Apesar de os aprendizes esperarem que todos os erros que cometiam fossem corrigidos, muitos demonstraram ter conhecimento de que a metodologia usada pelo

\footnotetext{
${ }^{2}$ A correção direta "implica marcar no texto os erros e fornecer a forma correta" (FIGUEIREDO, 1997, p. 118).
} 
professor não incentivava tais correções. Os aprendizes também demonstraram que esperavam uma correção não ameaçadora e que não os expusesse ao ridículo. Já os professores, em sua maioria, acreditavam que só deviam corrigir os erros após o aprendiz ter concluído seu pensamento, que deviam corrigir prioritariamente erros que dificultavam a comunicação e que não deviam corrigir o aprendiz mais de uma vez em uma mesma participação comunicativa. Os professores também acreditavam que a correção devia ser feita de forma polida para não inibir a fala do aprendiz e que, ocasionalmente, poderiam realizar a correção com os pares.

Lyrio (2001) conclui que as diferenças entre o pensamento dos professores e de seus alunos podem contribuir para uma reflexão sobre o processo de ensino e aprendizagem, visto que essas informações podem ajudar ambos a refletir sobre suas crenças à luz de teorias, as quais oferecem variedades de correções que podem se adequar às expectativas tanto dos professores quanto às de seus alunos.

A pesquisa de Ciocari (2002, p. 97) sobre tratamento de erro oral trouxe como resultado principal o fato de que os aprendizes "querem e desejam ser corrigidos". A autora também demonstrou que os alunos, participantes de seu estudo, queriam ser corrigidos de forma direta, individual, com explicações dos porquês de cada erro e sem sofrer constrangimento diante dos colegas.

Um outro estudo sobre tratamento de erros orais foi realizado por Cunha e Lima (2002). A investigação foi conduzida em duas turmas de LE, em uma escola particular, no Estado do Rio Grande do Sul. Os resultados mostraram que o grupo que tinha por professora uma falante nativa de LE recebeu menos correção do que a turma cuja professora era não-nativa. Os aprendizes eram favoráveis ao feedback corretivo como meio de se evitar a recorrência dos erros. Houve mais correções de erros que dificultavam a comunicação do que erros de forma. Observou-se, também, que houve mais correções diretas do que em pares e que se respeitava o término da fala do aprendiz para a realização das correções.

Esses estudos revelam que é importante que nós, professores, busquemos conhecer o que os alunos consideram como erro na aprendizagem de uma LE e como percebem a correção. Se tivermos consciência de nossas próprias crenças sobre essa temática e, também, 
das crenças dos aprendizes envolvidos em nossas aulas, poderemos analisar, comparar, refletir e elaborar ações que favoreçam a aprendizagem. Para tanto, é primordial conhecer não só o que constitui um erro, mas também algumas das diferentes formas de correção dentro do processo de ensino e aprendizagem de línguas. Dessa forma, apresentamos uma perspectiva diacrônica das definições de erro, segundo os estudos realizados por Figueiredo (1997) e Carvalho (2002), e acrescentaremos as definições propostas por Lewis (1993) e James (1998). Todos esses autores afirmam que definir erro não é uma tarefa fácil, pois o termo recebe significações e ressignificações, de acordo com a teoria lingüística que o sustenta. O Quadro 1 traz algumas dessas definições:

QUADRO 1

Algumas definições de erro no processo de ensino e aprendizagem de línguas

\begin{tabular}{|c|c|}
\hline Definições & Autores \\
\hline $\begin{array}{l}\text { Erro é um enunciado, forma, ou estrutura que o } \\
\text { professor de uma língua em particular considera } \\
\text { inaceitável por causa de seu uso inapropriado } \\
\text { ou sua ausência no discurso da vida real. }\end{array}$ & Hendrickson (1978) \\
\hline $\begin{array}{l}\text { Erro é tudo aquilo que foge à variedade que foi } \\
\text { eleita como exemplo de boa linguagem. }\end{array}$ & $\begin{array}{l}\text { Ilari e Possenti } \\
\text { (1985) }\end{array}$ \\
\hline $\begin{array}{l}\text { Erro é uma forma lingüística - ou combinações } \\
\text { de formas - que, no mesmo contexto e sob } \\
\text { condições semelhantes de produção, não seria, } \\
\text { de maneira alguma, produzida pelos falantes nativos. }\end{array}$ & Lennon (1991) \\
\hline $\begin{array}{l}\text { Erro é uma forma ou estrutura que o falante nativo } \\
\text { considera inaceitável por causa do uso impróprio. }\end{array}$ & Klassen (1991) \\
\hline Erro é um desvio de uma norma idealizada e inexistente. & Lewis (1993) \\
\hline $\begin{array}{l}\text { Erro é um fenômeno observável na aprendizagem } \\
\text { de uma língua estrangeira, que evidencia o que o } \\
\text { aluno já adquiriu e o que ele ainda não adquiriu } \\
\text { e não o que o professor pensa que ele adquiriu. }\end{array}$ & James (1998) \\
\hline
\end{tabular}

As definições de erro apresentadas nesse quadro demonstram que, até o início dos anos 1990, o erro possuía uma visão mais negativa do que positiva dentro das teorias lingüísticas. Após esse período, os erros passam a ser considerados como sinônimos de tentativas de uso da língua-alvo, 
passíveis de serem investigados e utilizados em favor da aprendizagem (ALLWRIGHT; BAILEY, 1991; LEE, 1997, FIGUEIREDO, 1997).

Nesse sentido, a correção passa, igualmente, a ser utilizada como um momento de interação e de aprendizagem, principalmente aquelas realizadas de forma indireta: a autocorreção, a correção com os pares, a correção no quadro-negro e a conferência (para uma visão ampla desses tipos de correção, veja Figueiredo, 1997, 2005).

\section{O estudo}

Os dois professores investigados neste estudo eram, no ano de 2003, ao mesmo tempo, alunos do $1^{\circ}$ ano do Curso de Letras Português/ Inglês, em um pólo da Universidade Estadual de Goiás, próximo a Goiânia, e professores da Rede Pública Estadual de Ensino na cidade que abriga esse pólo. A primeira participante escolheu o nome de Cíntia, e o segundo optou por Manuel, os quais, doravante, serão seus codinomes.

Realizamos o estudo em duas turmas de $3^{\circ}$ ano de Cíntia e duas turmas de $8^{\mathbf{a}}$ série de Manuel. Para a coleta de dados, foram utilizadas observações de campo de 32 horas-aula nas duas turmas de Cíntia e 40 horas-aula nos grupos de Manuel, das quais foram filmadas e transcritas 18 horas/aula ministradas por Cíntia, e 22 horas/aula por Manuel. Eles também responderam individualmente a um questionário, antes do início das observações em campo, e foram entrevistados, separadamente, após o término das filmagens, por um dos autores deste artigo.

A soma total de alunos assíduos nas 4 turmas era de aproximadamente 120. Apesar de todos terem participado das aulas observadas, contamos com a adesão de apenas 15 estudantes do Ensino Fundamental para responder ao questionário, e 8 para a entrevista. ${ }^{3}$ Quanto aos alunos do Ensino Médio, 7 responderam ao questionário, e 5 foram entrevistados. Tanto as entrevistas com os professores quanto com os alunos foram realizadas com a utilização do recurso de

\footnotetext{
${ }^{3}$ Os alunos que efetivamente participaram do estudo (responderam ao questionário e foram entrevistados) escolheram seus próprios codinomes. Os demais alunos da turma receberam uma numeração, por exemplo Aluno1, Aluno2 etc.
} 
visionamento das aulas filmadas, para que os participantes pudessem refletir sobre as ações desenvolvidas durante as aulas.

No intuito de averiguar como a correção escrita de fato ocorria nas turmas pesquisadas, recolhemos caderno, folhas de fichário, cadernoálbum ${ }^{4}$ e provas que os professores já haviam corrigido.

\section{Os resultados}

Iniciamos a análise apresentando as crenças relativas a erro e correção de Cíntia e de seus alunos. Posteriormente, apresentamos as de Manuel e de seus alunos.

\section{Inferindo crenças sobre correção de erros da professora Cíntia}

De acordo com Cíntia, o modo como seus professores de inglês ministravam as aulas não era eficaz, pois eles se preocupavam apenas com a forma e, portanto, desconsideravam o fato de ela estar ou não aprendendo a se comunicar em LE. Ela gostaria de ter tido oportunidades para o desenvolvimento das habilidades da fala e da leitura quando era aprendiz de LE na escola pública.

A professora afirma que, em suas aulas, utiliza textos com exercícios de interpretação, abordando a questão do ensino da gramática como algo que os alunos necessitam para a prova de Língua Estrangeira no vestibular, apesar de seus alunos não gostarem do estudo de regras gramaticais e preferirem estudar a língua contextualizada com a realidade deles.

Porém, mesmo tendo consciência de que a aprendizagem de regras não atende às expectativas de seus alunos, a participante lhes fornece esse conteúdo, recriando o contexto das aulas que teve como aprendiz.

Os alunos de Cíntia, como outros aprendizes, cometem erros ao elaborar hipóteses para testar sua aprendizagem. Porém, a professora

\footnotetext{
${ }^{4}$ Manuel e seus alunos chamam de caderno-álbum um caderno tipo ata que continha gravuras/figuras (de animais, objetos de casa ou escolares etc.) com seus respectivos nomes.
} 
parece não ter uma visão positiva dos erros de seus alunos. Ela não faz uso deles como suporte para a elaboração de estratégias eficazes à aprendizagem. Algumas das razões para tais procedimentos estão presentes nas crenças que descreveremos a seguir.

\section{Crença de que fornecer o modelo correto é uma correção eficaz}

Cíntia, ao corrigir os exercícios escritos, escreve as respostas corretas no quadro e as lê, geralmente em inglês, explicando-as novamente e traduzindo-as para o português. Nos momentos em que comenta algum item, por decisão própria ou para responder à indagação de algum aluno, ela não elicia deles a resposta. Ao contrário, Cíntia lhes fornece um modelo correto a ser repetido, ou seja, a resposta esperada. Mesmo sendo esse um procedimento de correção comumente observado em salas de aula, no caso de Cíntia, a crença de que tal procedimento é uma correção de fato eficiente impede que ela aja de outras maneiras. Desse modo, ela sempre se limita ao uso desse tipo de correção. O recorte a seguir mostra que Cíntia acredita que, se o professor fornecer ao aluno a forma correta, ele está contribuindo para que o aluno consiga não somente perceber o erro que cometeu, como também substituir esse erro pela forma correta.

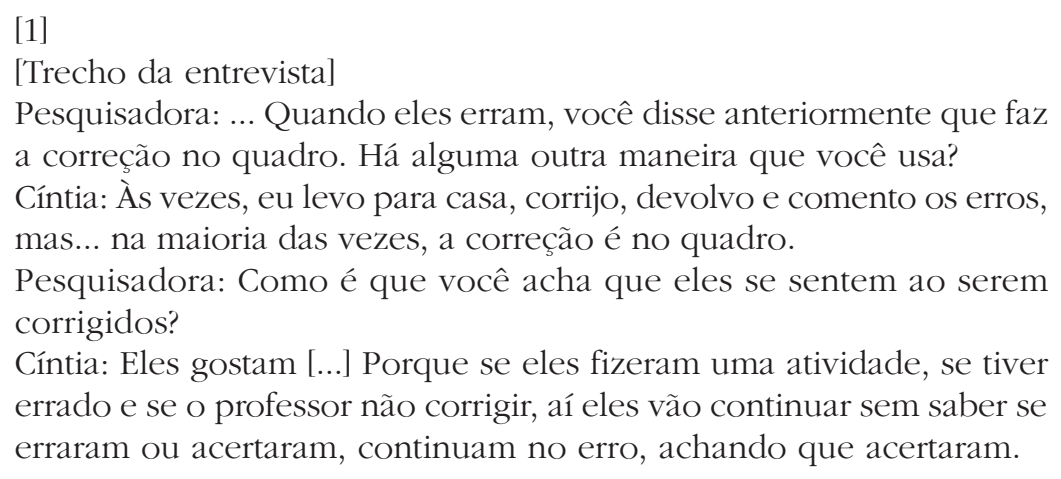
errado e se o professor não corrigir, aí eles vão continuar sem saber se erraram ou acertaram, continuam no erro, achando que acertaram.

Entre os alunos que responderam ao questionário, encontramos opiniões recorrentes de que falar as respostas ou escrevê-las no quadro é uma forma de correção. Mesmo que a professora não identifique os erros e apenas forneça as respostas corretas, os alunos acreditam estar sendo corrigidos, como podemos observar pelas seguintes respostas: 
[2]

[Pergunta do questionário]

A sua professora de inglês corrige as tarefas? Como?

Fernanda: Sim. Ela passa no quadro a resposta certa, e, se alguém tiver alguma dúvida, ela ajuda.

Maria: Ela corrige a tarefa no quadro.

Quanto à correção oral, Cíntia também a faz fornecendo a forma correta. Ela parece acreditar que a repetição de um modelo correto propicia uma aprendizagem oral eficiente.

As observações de sala de aula não nos permitem afirmar se fornecer a forma correta contribui ou não para a aprendizagem de LE. Porém, podemos afirmar que há alunos que já não compartilham a crença de que fornecer a forma correta seja uma correção eficaz. Eles acreditam que esse tipo de correção - oral e escrita - não é eficiente, conforme podemos verificar nas informações retiradas das respostas a uma das perguntas do questionário.

[3]

[Pergunta do questionário]

Como você avalia o modo como ela corrige as tarefas? Por quê?

Marcos: O modo é enjoativo, porque ela fala demais.

Maria: Muito mal, porque eu não aprendo nada.

Os alunos Marcos e Maria, por exemplo, consideram que a professora mantém o discurso centrado nela mesma quase todo o tempo. Ela não consegue perceber quem realmente entendeu o conteúdo e quem está com dúvidas, pois as respostas são fornecidas de modo generalizado, isto é, independentemente do fato de os aprendizes terem feito as atividades de modo correto ou não.

Concluímos a análise desta crença comentando que, se as crenças da professora vão ao encontro da crença dos alunos, e se sua metodologia também corresponde a essa crença, então eles podem possivelmente atingir suas expectativas, o que corrobora as afirmações de Kern (1995). Porém, se a crença da professora é conflituosa com a de seus alunos, eles poderão se sentir frustrados por não compreenderem o conteúdo e por não terem a oportunidade de manifestar suas opiniões, o que se coaduna com as afirmações de Horwitz (1985) e Johnson (1994). 


\section{Crença de que é o professor quem provê o modelo correto de lingua a ser seguido}

Quando Cíntia trabalha exercícios que não possuem um modelo correto de resposta, os alunos apresentam certa dificuldade em resolvêlos, pois esperam que ela thes forneça a resposta correta. Os trechos das aulas filmadas expressam essa crença. No exemplo 4, Cíntia está fazendo a correção oral de uma prova que oferece três questões relacionadas ao texto. A primeira é "Resumindo em apenas uma palavra, o texto trata de qual questão?"

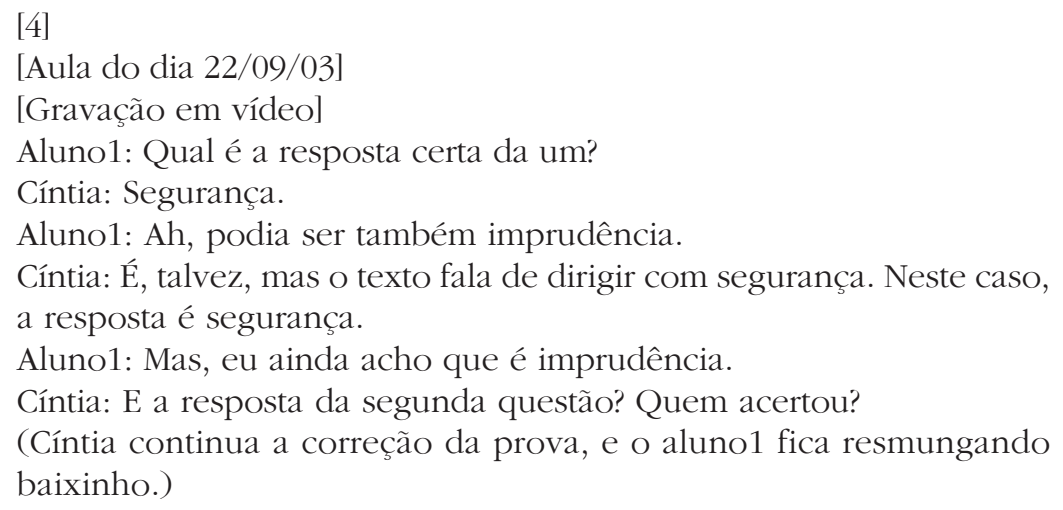

Cíntia não aceitou a resposta do aluno por não ser o modelo correto de resposta que ela esperava. Apesar de o aluno não ter concordado com ela, como pudemos observar por meio de seus resmungos, ele não soube defender seu ponto de vista. O trecho analisado nos remete à relação hierárquica entre professor e aluno e ao fato de o ensino fundamentar-se na idéia de ser o professor o modelo correto a ser seguido.

A crença de Cíntia de que os conceitos dos alunos não correspondem à resposta correta se manifestou na ação dela ao optar por seguir exclusivamente sua própria opinião de qual seria o vocábulo apropriado para responder à questão da prova. Mesmo que ela estivesse seguindo o modelo oferecido pelo livro didático, essa escolha expressa sua crença de que há um modelo correto a ser seguido. Esses fatos corroboram as afirmações de Leffa (1991) e de Nespor (1987) de que as crenças podem fazer com que os professores sejam menos flexíveis e menos abertos a receber possíveis contribuições de seus alunos. 


\section{Crença de que evidenciar o erro é constranger o aluno}

Nas aulas observadas, percebemos que havia correção individual, oral ou escrita, quando o aluno, voluntariamente, perguntava algo à professora ou quando ela percebia que o aprendiz havia falado ou escrito algo incorretamente. Se o aluno tomava a iniciativa de expor o erro que havia cometido, a professora se dirigia a ele e o corrigia fornecendo a forma correta. Todavia, nos momentos em que ela percebia o erro oral de algum aluno, a correção era feita de forma direta, porém implícita. A professora escrevia a resposta correta no quadro ou a falava, para correção escrita. O único tipo de correção oral observada, durante o período em que acompanhamos as aulas da participante, foi a correção de pronúncia. Quando percebia erros de pronúncia, Cíntia repetia as palavras, segundo o parâmetro de sua própria forma de pronunciar, o que confirma as afirmações de Allwright e Bailey (1991) e Cunha e Lima (2002) de que, em contexto formal de sala de aula, o parâmetro para o ensino de uma LE geralmente é o da norma falada pelo professor. Os recortes da fala de Karina e Louraine confirmam que a participante faz a correção de pronúncia. No caso de Karina e Louraine, são elas mesmas que solicitam a correção. Portanto, a correção é feita individualmente.

[5]

[Pergunta do questionário]

A sua professora de inglês corrige você oralmente? Em quais momentos ela o faz?

Karina: Quando eu erro na maneira de expressar. Eu pergunto e ela me ensina a maneira correta de pronunciar a palavra ou, até mesmo, a frase.

[6]

[Trecho da entrevista]

Pesquisadora: E você perguntava ou você não perguntava?

Louraine: Às vezes sim, quando eu ficava muito em dúvida, porque igual o som de "th", nossa! É uma dificuldade para eu falar. Então, sempre eu estava perguntando.

As alunas Karina e Louraine não compartilham a crença de que evidenciar o erro é expor o aluno. Elas não se sentem constrangidas por cometer erros. Ao contrário, solicitam a correção, o que corrobora as afirmações de Schulz (1996) de que o aluno quer ser corrigido, porque considera a correção importante para sua aprendizagem. 
Por outro lado, Cíntia acredita que, se ela solicitasse, explicitamente, que o aluno repetisse a pronúncia correta, ela o estaria expondo diante dos colegas, os quais poderiam criticá-lo. Portanto, ela opta pela correção oral direta e implícita, visto que esse é um meio efetivo de evitar a exposição do erro que o aluno cometeu. Ela o corrige imediatamente após ouvir a pronúncia incorreta, mas não solicita que ele repita o modelo correto. O exemplo a seguir confirma nossas colocações.

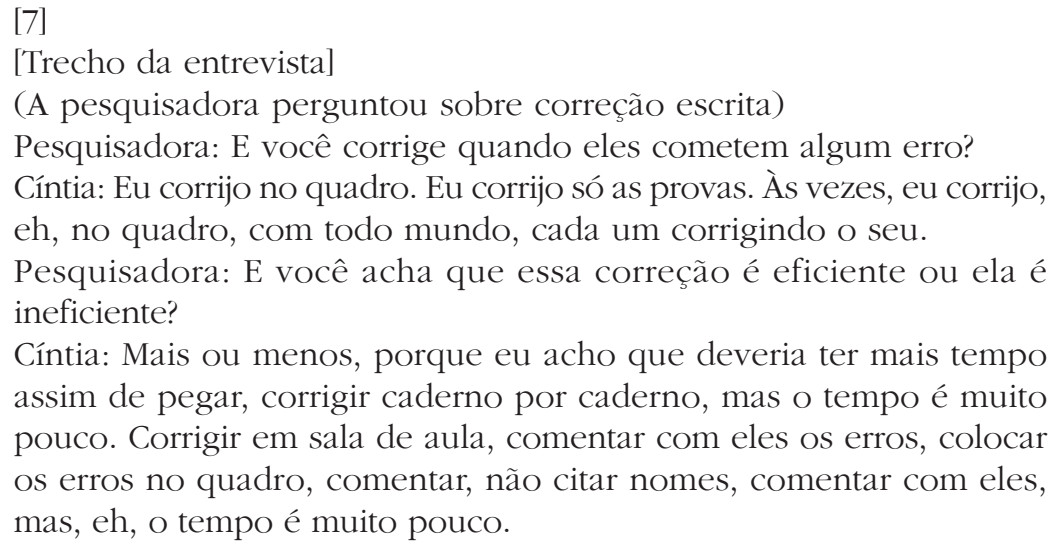
assim de pegar, corrigir caderno por caderno, mas o tempo é muito pouco. Corrigir em sala de aula, comentar com eles os erros, colocar os erros no quadro, comentar, não citar nomes, comentar com eles, mas, eh, o tempo é muito pouco.

A participante revela que aplica o mesmo tipo de correção às atividades escritas, isto é, ela escreve as respostas corretas no quadro. Desse modo, ela não cita os nomes dos alunos que cometeram os erros.

Alguns alunos afirmaram que se sentiriam constrangidos diante dos colegas se seus erros fossem corrigidos pela professora de forma explícita em sala de aula. Observamos que esses aprendizes preferem questionar suas dúvidas com outro colega ou simplesmente copiar as respostas do quadro. O exemplo seguinte mostra como a aluna Maria se sentiu embaraçada ao solicitar explicitamente uma correção e como ela passou a agir para evitar situações constrangedoras.

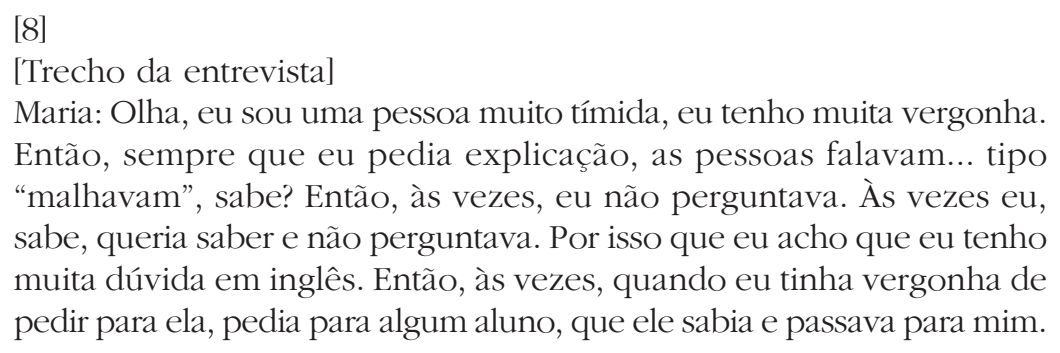


Maria provavelmente se sente mais à vontade com alguns de seus colegas, com os quais ela tem uma relação afetiva mais próxima. Então, prefere esclarecer suas dúvidas com eles a se dirigir à professora e correr o risco de ser ridicularizada por ter seus erros expostos durante as aulas. Por outro lado, há outros alunos que voluntariamente solicitam correção. Eles parecem não compartilhar de tais sentimentos e ações, uma vez que assumem os erros que cometeram e pedem à professora esclarecimentos sobre eles. Não observamos, em momento algum, críticas negativas aos alunos que pediram à professora esclarecimento de dúvidas e concluímos que tal atitude parece protegê-los das críticas desconstrutivas de seus colegas, diferentemente do que nos relatou Maria.

As observações e as filmagens das aulas de Cíntia confirmam que ela realiza a correção na sala de aula de forma generalizante, principalmente para evitar a exposição dos erros de seus alunos. Durante as aulas que acompanhamos, ela nunca revelou o erro de um aluno citando seu nome e o erro cometido. A visão negativa de erro é bastante presente na prática de Cíntia, mesmo que ela não tenha dito isso claramente. Ela evita direcionar o erro a qualquer aluno que seja, pois acredita que todos eles também compartilham a idéia de que errar é algo negativo: expor os erros é colocar o aluno em uma situação embaraçosa. Porém, o fato de alguns alunos pedirem para a professora solucionar suas dúvidas comprova que, para eles, o erro é sinônimo de que estão elaborando hipóteses sobre a LE, e, portanto, parece-nos que não se incomodariam de ser corrigidos.

Crença de que a tradução, além de facilitar a aprendizagem, é um meio efetivo de prevenir erros

Cíntia acredita que, independentemente do conteúdo, o aluno aprende em uma seqüência pré-determinada, passo a passo. O primeiro passo é mostrar ao aluno o que existe de semelhante entre a língua materna e a língua estrangeira, como, por exemplo, as palavras cognatas, chamadas por ela e pelos alunos de "palavras transparentes". Tal procedimento facilita aos alunos a compreensão dos textos em LE e, por conseguinte, a resolução dos exercícios sem risco de cometerem erros, como podemos observar no recorte de uma de suas aulas. Cíntia entrega aos alunos algumas cópias de um texto e pede para eles escreverem o título nelas. Em seguida, pede aos alunos que localizem as palavras cognatas no texto: 
[9]

[Aula do dia 26/11/03]

[Gravação em vídeo]

Cíntia: Gente, coloca o título aí, ainda quem não tem: television.

Cíntia: Vocês conhecem a origem da televisão? E o futuro? Como será o futuro da televisão?

(Cíntia lê a introdução do texto.)

Cíntia: Dêem uma olhada no texto. Vamos verificar as transparent words. Vamos ver as palavras transparentes.

A crença descrita neste subitem é compartilhada por Cíntia e por alguns de seus alunos, que acreditam ser a compreensão geral das idéias de um texto suficiente para a aprendizagem de inglês. Esses alunos consideram que vão precisar da língua inglesa primordialmente para responder à prova de vestibular e, nessa prova, precisarão compreender a idéia geral do texto para identificar a opção correta.

O exemplo a seguir retrata um exercício de completar frases com palavras do texto. A professora pediu aos alunos que o lessem e respondessem às questões. As alternativas ofereciam as opções de escolha entre as letras a, b ou c.

\section{[10]}

[Aula do dia 22/09/03]

[Gravação em vídeo]

Cíntia: Eu vou ler o exercício com vocês, só que vocês é que vão responder.

Aluno2: Ah! Se você não vai falar como é que eu vou saber?

Aluna3: No número 1 é a letra c.

Cíntia: I don't know.

Aluna3: Ah, não! Tem que ler o texto. Como eu vou saber se eu não tenho a tradução?

(Cíntia vai até a carteira da aluna e lê com ela, traduzindo o texto. A aluna, então, consegue responder ao exercício corretamente.)

(Outro aluno questiona a professora sobre a resposta de outro item.) Aluno4: Qual é a letra do número 4? Oh, professora, traduz!

(Ela repete o procedimento anterior e traduz o trecho do texto que contém a resposta, só que, dessa vez, para todos os alunos.)

Esse exemplo confirma, mais uma vez, como os alunos, já habituados a utilizar o recurso de tradução, ficam insatisfeitos quando ela não lhes é fornecida. Tal fato sugere uma visão restrita não apenas 
das estratégias de leitura e do condicionamento a apenas uma delas - a tradução linear para a língua portuguesa-, mas do que seja língua. Essa crença corrobora as afirmações de Johnson (1994) de que, geralmente, o professor percebe, sente e age conforme o que ele acredita ser eficaz. As conseqüências incluem o fato de esse professor restringir sua prática a alguns recursos didáticos que nem sempre atendem às expectativas dos alunos. Tal procedimento pode minimizar a aprendizagem deles, pois, por não se identificarem com as ações do professor e não conseguirem encontrar outros meios para a aprendizagem, poderão se sentir fracassados, e, por conseguinte, culpar o professor, a si mesmos ou até mesmo o fato de terem na grade curricular uma LE. Johnson (1994) sugere que uma abordagem reflexiva é importante para contestar um modelo de treinamento. Nossa participante emprega a idéia de que treinar a tradução é suficiente para inferir os significados e as regras de uso da LE, o que se torna, conseqüentemente, um meio eficiente para evitar que os alunos cometam erros.

\section{Inferindo crenças sobre correção de erros do professor Manuel}

Manuel passou quase toda sua infância no Estado do Piauí. Ao se mudar para Goiás, começou a cursar a sexta série do Ensino Fundamental, onde ocorreu seu primeiro contato com o estudo formal da língua. Ele achava que aprender inglês era algo muito difícil, pois sempre tirava notas baixas e ficava em recuperação. Sua experiência de aprendizagem foi negativa, sentindo-se frustrado e com medo dos professores. Dessa forma, associou a aprendizagem de inglês a situações de sofrimento e de dor. Sentia-se reprimido pelos professores de inglês, os quais lhe ensinavam regras gramaticais de modo descontextualizado. Ele acreditava que a tradução lhe facilitaria a compreensão do conteúdo ministrado, mas os professores não a utilizavam. Sentia-se humilhado pela correção feita por seus professores, que o expunham em sala de aula.

Manuel, ao contrário de Cíntia, não reproduz exatamente a prática de sala de aula observada nas aulas de seus professores de inglês nos Ensinos Fundamental e Médio. Ele age de modo inverso da prática de seus professores de LE. Por ter sido um aprendiz que teve uma trajetória difícil no processo de aprendizagem de LE, Manuel faz tudo para não 
deixar que seus alunos passem pelas dificuldades por que passou nesse processo. Dessa forma, ele fornece o texto em inglês e a tradução, bem como trabalha com questões de interpretação, cujas respostas ele mesmo fornece. Ele explica os pontos gramaticais, passa no quadro os exercícios acompanhados de um modelo de resposta para cada questão, lê item por item, respondendo a todo o exercício oralmente e, em seguida, por escrito.

A aula de Manuel é centrada nele mesmo. Ele impede que seus alunos demonstrem seu nível de interlíngua, pois não lhes proporciona oportunidades para testar hipóteses sobre a língua que estão aprendendo. No recorte de um trecho da entrevista, notamos que ele nos fala sobre o cuidado que tem ao fazer uma correção, pois, segundo ele, se a correção for direcionada a um aluno em particular, esse aluno a perceberá como uma imposição do professor, isto é, como uma punição. Desse modo, a correção seria um instrumento que causa dor e, por conseguinte, sofrimento, como pode ser observado no seguinte exemplo.

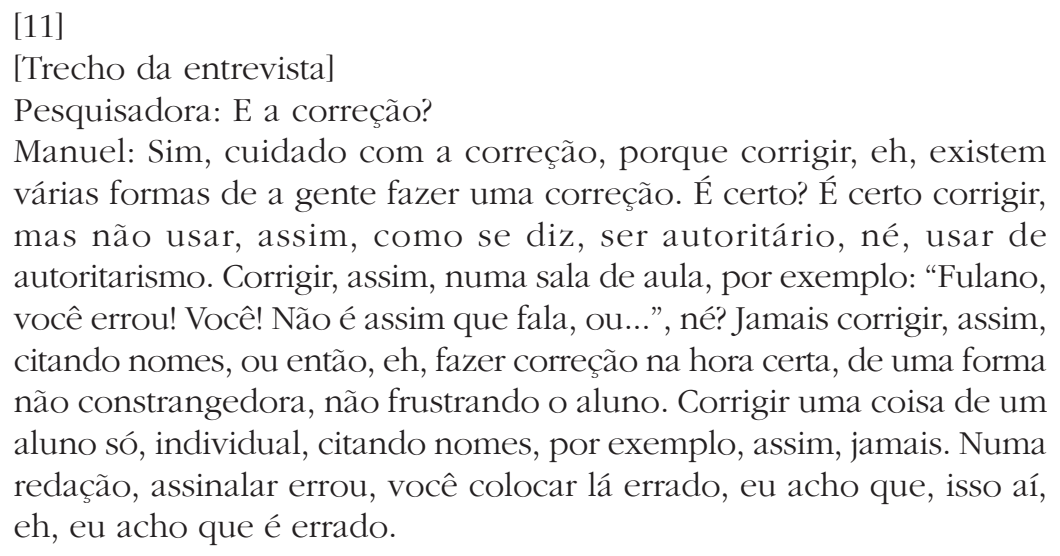
várias formas de a gente fazer uma correção. É certo? É certo corrigir, mas não usar, assim, como se diz, ser autoritário, né, usar de autoritarismo. Corrigir, assim, numa sala de aula, por exemplo: "Fulano, você errou! Você! Não é assim que fala, ou...", né? Jamais corrigir, assim, citando nomes, ou então, eh, fazer correção na hora certa, de uma forma não constrangedora, não frustrando o aluno. Corrigir uma coisa de um aluno só, individual, citando nomes, por exemplo, assim, jamais. Numa redação, assinalar errou, você colocar lá errado, eu acho que, isso aí, eh, eu acho que é errado.

Manuel desenvolve sua prática cotidiana em sala de aula no sentido de sempre facilitar a aprendizagem de seus alunos. Ele acredita que facilitar a aprendizagem é fornecer os conteúdos, as atividades, as respostas das atividades, a leitura e instrumentos avaliativos simplificados, como colagem de figuras e criação de cartazes sobre datas comemorativas. Todas essas ações possuem o objetivo de evitar que seus alunos sofram como ele sofreu para aprender a língua inglesa. Porém, o que se observa é que Manuel impede que seus alunos se tornem responsáveis pela aprendizagem da LE. Manuel se sentiu excluído do processo de ensino 
e aprendizagem pelas dificuldades que enfrentou e evita que seus alunos sofram. Portanto, procura protegê-los das dificuldades com que possam se deparar durante o processo de aprender uma LE. São suas crenças, conforme nos afirmam Pajares (1992), Johnson (1994) e Frey (2002), que conduzem sua prática. Dentre essas crenças, buscaremos analisar, nos subitens a seguir, especificamente aquelas relacionadas à correção de erros.

Crença de que facilitar a aprendizagem é fornecer ao aprendiz a forma correta

Manuel fornece as respostas a seus alunos por acreditar que a LE é tão difícil para eles que ele precisa facilitar-lhes a aprendizagem. Essa crença influencia diretamente o que Manuel diz e faz em sala de aula.

O recorte a seguir mostra que Manuel considera que fornecer a resposta ao aluno é o mesmo que correção e que tal atitude é a que deve ser seguida. Sua crença de que fornecer a forma correta facilita a aprendizagem está tão arraigada em suas experiências pessoais, como sugere Horwitz (1985), que ele não consegue perceber que seus alunos possam preferir outras formas de correção.

\section{[12]}

[Trecho da entrevista]

Manuel: Quando eu faço a correção, eu vou explicando de novo, porque que aquilo ali é daquele jeito. Então, de novo, porque que aquilo ali é daquele jeito. Aí, todos fazem a correção, têm a chance de corrigir, de apagar o erro e corrigir. Então, não tem como eles não corrigirem. Eu faço a correção no quadro e eles copiam a resposta correta.

Alguns dos alunos de Manuel não compartilham sua crença de que a aprendizagem deve ser facilitada pelo recebimento da forma correta. Eles manifestaram desejo de ter a oportunidade de fazer os exercícios por eles mesmos, cometendo ou não erros, pois, para eles, diferentemente de Manuel, os erros não parecem ser sinônimos de sofrimento, mas, sim, de aprendizagem. O exemplo seguinte ilustra como Marques gostaria de ter tempo para responder aos exercícios, pois, assim, teria a chance de aprender a língua inglesa. Ele gostaria que o professor permitisse que ele participasse da construção de seu conhecimento e não lhe fornecesse tudo já construído. 


\begin{abstract}
[13]
[Trecho da entrevista]

Marques: Eu acho que, assim, ele passava as tarefas, não dava nem tempo de a gente responder direito e ele já passava as respostas. Então, isso era mais um motivo para a gente não aprender. É assim, sabe, eu acho que a gente tem que procurar a resposta, e se não achar, a gente pergunta a ele. Mas a gente tem que ser incentivado a procurar a gente mesmo as respostas. No caso, ele passava e não esperava nem um pouquinho para a gente responder, sabe? No caso, eu acho que ele devia passar a tarefa e, na próxima aula, ele passar as respostas.
\end{abstract}

Os relatos a seguir mostram que há alunos, no entanto, que consideram o fato de ele escrever antecipadamente as respostas no quadro como positivo, pois acreditam que esse é um caminho eficaz para aprender inglês. Isto corrobora as afirmações de Abelson (1979) de que as crenças não são unânimes dentro de um mesmo grupo ou de uma mesma comunidade.

\title{
[14]
}

[Pergunta do questionário]

Como você avalia o modo como ele corrige as tarefas? Por quê?

Weslei: Bom, porque dessa forma o aluno aprende mais.

\section{[15]}

[Trecho da entrevista]

Cecília: É porque fica mais fácil para a gente aprender, passar, deixar para a outra aula a gente já esquece o texto em inglês que a gente sabe.

Manuel não tem a intenção de criar conflitos em sala de aula. Ao contrário, acredita estar agradando os alunos ao lhes oferecer o conhecimento pronto. Porém, nem todos os aprendizes querem receber o conhecimento dessa forma, pois eles gostariam de ter a oportunidade de opinar sobre a metodologia escolhida para sua aprendizagem, bem como dividir com Manuel a responsabilidade pelo que aprendem, como é ilustrado a seguir.

[16]

[Trecho da entrevista]

Tânia: Por exemplo, nós tivemos muita mordomia, mordomia [...], bem, agora a gente vai para o primeiro ano... a gente está pensando, porque não aprendeu? Ou não houve uma certa preocupação do professor 
de estar passando isso para a gente? [...] Eu acho assim, que ele devia sempre estar perguntando a gente o que a gente acha, sabe? Assim... o que devia apresentar ou não. Porque somos nós que vamos aprender. [...]

Esse desencontro de pensamentos corrobora as afirmações de Richards e Lockhart (1996) de que os aprendizes, tal como os professores, trazem para o contexto formal de ensino suas crenças, e de que estas afetam a maneira como eles abordam o processo de ensino e aprendizagem. Tanto Kern (1995) quanto Pintrich, Marx e Boyle (1993) comentam a importância de discussões entre aprendizes e professores sobre aprendizagem de línguas. Por meio do diálogo, Manuel poderia expor o modo como ele acredita ser melhor para seus alunos aprenderem a LE, e seus alunos, a maneira como eles acham ser mais efetiva para aprender a língua inglesa e, juntos, decidirem quais são os melhores caminhos para uma aprendizagem efetiva.

Podemos concluir que a crença, mostrada neste subitem, revela que Manuel não propicia a seus alunos a oportunidade de fazer as atividades. Isto faz com que ele não conheça o grau de interlíngua de seus alunos, visto que ele não faz uso dos erros dos aprendizes como pistas para o planejamento de suas aulas e para a elaboração de atividades que possam realmente contribuir para a eficácia da aprendizagem deles de LE.

Os alunos, por sua vez, podem se adaptar ou não ao fato de não terem de se esforçar para responder às atividades. Alguns podem até fazer de tal fato um hábito e não saber como proceder diferentemente. Outros, mesmo não concordando em receber todas as respostas, podem se sentir sem alternativas diante das ações do professor.

\section{Crença de que dar visto nas atividades substitui a correção}

O único contato com as atividades escritas pelos alunos é no final de cada bimestre quando Manuel chama aluno por aluno, seguindo a ordem dos nomes do diário, pedindo-lhes que tragam o caderno de atividades para ser avaliado. Ele folheia página por página do caderno e conta as tarefas do bimestre em questão. Então, coloca visto e sinais indicativos de que os cadernos estão completos ou não. Para o professor, esse momento fornece ao aluno motivação para a aprendizagem de LE, como podemos observar no trecho seguinte. 


\begin{abstract}
[17]
[Trecho da entrevista]

Manuel: O visto, eu olho o conteúdo, os textos, as atividades e daí eu passo, eu vou marcando lá, um vezinho ou um tracinho, mas eu olho página por página, todas as atividades. Nas que ficaram sem responder, eu coloco uma interrogação. Não dá para responder cada uma, ali, no momento, porque são muitos que deixam algumas sem responder, principalmente os menos interessados. E no final, até a aula atual, a última aula que eu dei, eu coloco um visto, que chamo de visto geral. É onde eu ponho a data, ponho minha rubrica, coloco lá, completo e escrevo alguma coisa que deixa ele estimulado: congratulations, very good.
\end{abstract}

Os alunos, no entanto, sabem que o professor, ao folhear os cadernos, não consegue perceber realmente o que está escrito. Então, alguns deles copiam outras atividades como sendo daquele bimestre e as entregam ao professor. Johnson (1994) afirma que os professores precisam reconhecer as crenças que possuem sobre eles mesmos como professores e sobre o processo de ensino e aprendizagem, pois, desse modo, poderiam refletir sobre as próprias práticas. Conseqüentemente, perceberiam se existe inconsistência entre as ações e a prática em sala de aula. No caso de Manuel, ele não percebe que seus alunos estão conscientes de que, apesar de afirmar saber o que cada aluno possui no caderno, na realidade ele não sabe. Os comentários dos alunos Leopoldo e Tânia confirmam esse fato.

[18]

[Trecho da entrevista]

Leopoldo: É, ele conta as tarefas. Até eu fiz uma sacanagem, que eu não tinha tantas tarefas e peguei as tarefas do $1^{\circ}$ bimestre, eh, e a gente estava no $4^{\circ}$, e só sei que passei para o $4^{\circ}$. Ele só contou as tarefas e nem percebeu.

[19]

[Trecho da entrevista]

Tânia: Assim, por exemplo, quando ele está..., ele nem olha o que a gente respondeu. Podia escrever abobrinha lá que ele dava visto e nota, tudo bom. Por exemplo, se escreve qualquer, se você repete só a frase em inglês, dá. Ele nem olha, por exemplo, se está certo, se está com algum erro e dá visto, dá nota. Por exemplo, o aluno que não está nem aí, só ir lá, repetir a frase, como eu já vi nos cadernos de meus outros colegas também, que eu olho e vejo um trem vazio, assim, mais sem lógica, com visto lá, ganhando nota do mesmo jeito de quem faz o certo. 
Eu acho assim, o professor, ele tem que saber no que ele está dando o visto e se tiver algum erro, corrigir o que não fez certo, manda fazer de novo, se não, não aprende.

Há um conflito entre as expectativas dos alunos e as ações de Manuel, não apenas pelo fato de os aprendizes perceberem que o professor não corrige as tarefas, mas também porque eles gostariam de ser corrigidos. Como a correção é inexistente, esses alunos se sentem menosprezados pelo professor que apenas passa as páginas sem verificar se as atividades estão certas ou erradas.

Essa discrepância entre o modo de Manuel fazer a correção e o modo como alguns alunos gostariam que ela fosse feita afeta o relacionamento entre Manuel e alguns de seus alunos. Esses alunos esperavam que Manuel fosse o mediador entre eles e a LE e que lhes possibilitasse ser aprendizes produtivos na construção do conhecimento da língua-alvo. Os alunos que esperavam que seus erros fossem corrigidos se sentem constrangidos pela ação de Manuel, ou seja, pela ausência de correção, de interação com o professor e provavelmente com seus colegas, como notamos pelos seguintes depoimentos dos alunos Marques e Gabriela.

\section{[20]}

[Trecho da entrevista]

Marques: Olha, eu acho que devia ter mais participação dos alunos. No caso dele, por exemplo, ele passar a matéria e perguntar mais para os alunos, porque ele passava só no quadro e ia embora, entendeu? Eu acho que ele devia passar e explicar para os alunos. Bem que ele explicava, mas não fazia perguntas sobre a matéria para os alunos. Eu acho que devia ter mais uma participação maior dos alunos quanto à matéria.

\section{[21]}

[Trecho da entrevista]

Gabriela: Pelo que eu saiba, ele tem que olhar, ver o que tinha errado e falar, falar o que estava errado e como que fazia.

Como mencionamos anteriormente, Manuel, quando era aprendiz de língua inglesa, não gostava quando seus professores o expunham diante de seus colegas ao corrigi-lo. Ele se sentia constrangido com isso. Portanto, evita que seus alunos experienciem o que ele experienciou, 
o que corrobora as afirmações de Pajares (1992), Johnson (1994, 1999) e Richards e Lockhart (1996) de que os professores possuem crenças adquiridas e baseadas nas imagens e nas experiências que tiveram quando eram aprendizes.

Há, no entanto, alunos que consideram o modo como ele corrige eficiente. Por conseguinte, acreditam que Manuel está acompanhando a aprendizagem deles, conforme nos mostram as afirmações dos alunos Marcos e Pâmela.

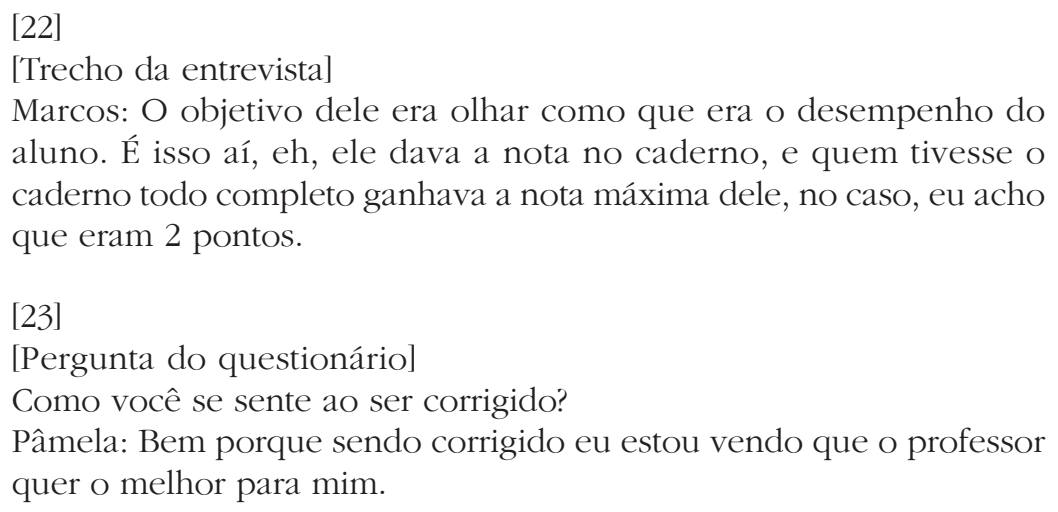
aluno. É isso aí, eh, ele dava a nota no caderno, e quem tivesse o caderno todo completo ganhava a nota máxima dele, no caso, eu acho que eram 2 pontos.

[23]

[Pergunta do questionário]

Como você se sente ao ser corrigido?

Pâmela: Bem porque sendo corrigido eu estou vendo que o professor quer o melhor para mim.

Manuel segue suas crenças sem refletir de que forma elas influenciam sua prática como professor de LE, sem analisar quais funções suas crenças desempenham em suas aulas. Ele as segue por acreditar que são facilitadoras à aprendizagem de LE de seus alunos. Então, continua reproduzindo o contexto que acredita ser o melhor para os aprendizes, mas, tal como seus professores faziam, Manuel não interage com seus alunos para saber o que eles pensam, como eles gostariam que fossem ministradas as aulas, quais são as crenças deles e de que forma elas poderiam ajudá-los a aprender a LE de modo mais efetivo.

\section{Algumas considerações}

Por meio deste estudo, pudemos observar que as ações dos professores, no que concerne à correção de erros, ora reavivam as experiências que tiveram quando eram alunos, ora as invertem. 
No contexto das aulas de Cíntia, observamos que ela reproduz suas experiências de aprendizagem de LE, as quais enfatizavam a forma, a tradução e conteúdos gramaticais. Suas crenças revelam uma visão de que o produto final de aprendizagem para os alunos que terminam o Ensino Médio é a prova de vestibular, de que a tradução facilita a compreensão textual e evita a produção de erros, bem como de que é possível evitar constrangimentos aos alunos pela não-exposição dos erros por eles cometidos.

Manuel, por sua vez, quando era aluno na escola pública, viu-se humilhado e ridicularizado por seus professores de inglês que não conseguiam perceber o quanto ele tinha dificuldades para aprender a LE. Sempre com notas abaixo da média e de personalidade introvertida, carregava, como uma "cruz", suas dúvidas e sua frustração por não aprender inglês. Como professor, busca reverter sua própria história de aprendiz de LE. As atitudes de seus professores, dificultando-lhe a aprendizagem, seriam, pois, convertidas em facilitação para seus alunos. Por ter experienciado a cobrança de ter de falar em LE, inverte essa experiência em suas aulas, sempre traduzindo tudo para língua materna, facilitando para seus alunos a compreensão da LE. Para tanto, oferece as respostas de todos os exercícios e a tradução dos textos para seus alunos, buscando, assim, a cumplicidade para o que ele acredita ser bom para eles.

Leffa (1991) e Richards e Lockhart (1996) afirmam que a conscientização de parte dos professores e dos aprendizes sobre as crenças que trazem para a sala de aula é fundamental para que haja uma maior compreensão do que seja aprender e ensinar uma LE. Portanto, é indispensável que o professor tenha, principalmente no seu curso de graduação, a oportunidade de trabalhar com suas crenças e, assim, com sustentação teórica, estender a seus alunos seu conhecimento, podendo, juntos, discutir e refletir sobre elas e ressignificá-las se considerarem necessário.

É igualmente importante que sejam feitas discussões e reflexões a respeito do papel do erro e da correção no processo de ensino e aprendizagem de línguas, e que os professores cultivem a idéia de que os erros fazem parte do processo de qualquer aprendizagem e de que a correção serve para mostrar caminhos, para aprimorar a aprendizagem e não para evidenciar fraquezas e insucessos. 


\section{Referências Bibliográficas}

ABELSON, R. P. Difference between belief and knowledge systems. Cognitive Science, v. 3, p. 355-366, 1979.

ALLWRIGHT, D.; BAILEY, K. M. Focus on the language classroom: an introduction to classroom research for language teachers. Oxford: Oxford University Press, 1991.

BARCELOS, A. M. F. A cultura de aprender lingua estrangeira (inglês) de alunos de Letras. 1995. Dissertação (Mestrado em Lingüística Aplicada) Instituto de Estudos da Linguagem, UNICAMP, Campinas, 1995.

A cultura de aprender línguas (inglês) de alunos no curso de Letras. In: ALMEIDA FILHO, J. C. P. de. (Org.). O professor de lingua estrangeira em formação. São Paulo: Pontes, 1999. p. 157-177.

. Metodologia de pesquisa das crenças sobre aprendizagem de línguas: estado da arte. Revista Brasileira de Lingüistica Aplicada, v. 1, n. 1, p. 7192, 2001.

. Crenças sobre aprendizagem de línguas, Lingüística Aplicada e ensino de línguas. Linguagem e Ensino, Pelotas, v. 7, n. 1, p. 123-156, $2004 a$.

Ser professor de inglês: crenças, expectativas e dificuldades dos alunos de Letras. In: VIEIRA ABRAHÃO, M. H. (Org.). Prática de ensino de língua estrangeira: experiências e reflexões. Campinas: Pontes, 2004b. p. 11-29.

BARCELOS, A. M. F.; VIEIRA ABRAHÃO, M. H. (Org.). Crenças e ensino de linguas: foco no professor, no aluno e na formação de professores. São Paulo: Pontes, 2006.

CARVALHO, G. de O. Revisão colaborativa de textos escritos em lingua inglesa por alunos iniciantes do curso de Letras. 2002. Dissertação (Mestrado em Letras e Lingüística), Faculdade de Letras, Universidade Federal de Goiás, Goiânia, 2002.

CIOCARI, R. M. O tratamento do erro oral em sala de aula de língua inglesa como língua estrangeira: a percepção do aluno. In: STURM, L.; ARAÚJO, D. de D. (Org.). Século XXI: um novo olhar sobre o ensino e a aprendizagem de línguas estrangeiras. Passo Fundo: UPF, 2002. p. 90-99.

CUNHA, A. P. de A.; LIMA, M. dos S. O tratamento de erros orais em sala de aula de inglês como LE. In: LIMA, M. dos S. (Org.). A lingua estrangeira em sala de aula: pesquisando o processo e o produto. Porto Alegre: Sagra Luzzatto, 2002. p. 9-28. 
FIGUEIREDO, F. J. Q. de. Aprendendo com os erros: uma perspectiva comunicativa de ensino de línguas. Goiânia: Ed. da UFG, 1997.

Semeando a interação: a revisão dialógica de textos escritos em língua estrangeira. Goiânia: Ed. da UFG, 2005.

FREITAS, M. A. de. Avaliação enquanto análise: resultados das primeiras reflexões do professor de LE sobre o próprio ensino. In: ALMEIDA FILHO, J. C. P. de (Org.). Oprofessor de lingua estrangeira em formação. São Paulo: Pontes, 1999. p. 51-62.

FREITAS, M. A. de; BELINCANTA, C. I.; CORRÊA, H. C. M. O. Professores de língua inglesa em formação: mudando crenças e atitudes. Trabalhos em Lingüistica Aplicada, n. 39, p. 47-67, 2002.

FREY, N. Ensinar/Aprender Línguas. Formas e Linguagem, ano 1, n. 4, p. 159-171, 2002.

HENDRICKSON, J. M. Error correction in foreign language teaching: recent theory, research, and practice. The Modern Language Journal, v. 62, p. 387-398, 1978.

HORWITZ, E. K. Using student beliefs about language learning and teaching in the foreign language methods course. Foreign Language Annals, v. 18, n. 4, p. 333-340, 1985.

. The beliefs about language learning of beginning university foreign language students. The Modern Language Journal, v. 72, n. 3, p. 283-294, 1988.

Cultural and situational influences on foreign language learners' beliefs about language learning: a review of BALLI studies. System, v. 27, p. $557-576,1999$.

ILARI, R.; POSSENTI, S. Português e ensino de gramática. Publicação do Projeto Ipê, p. 1-12, 1985.

JAMES, C. Errors in language learning and use: exploring error analysis. London and New York: Longman, 1998.

JOHNSON, K. E. The emerging beliefs and instructional practices of preservice english as a second language teachers. Teaching and Teacher Education, v. 10, n. 4, p. 439-452, 1994.

. Teachers' beliefs: the rock we stand on. In: JOHNSON, K. E. (Ed.). Understanding language teaching - reasoning in action. Boston: Heinle and Heinle Publishers, 1999. 
KERN, R. G. Students and teacher's beliefs about language learning. Foreign Language Annals, v. 28, n. 1, p. 71-92, 1995.

KLASSEN, J. Using student errors for teaching. English Language Forum, v. XXIX, n. 1, p. 10-16, 1991.

LEE, I. ESL learners' performance in error correction in writing: some implications for teaching. System, v. 25, n. 4, p. 465-477, 1997.

. L2 writing teacher's perspectives, practices and problems regarding error feedback. Assessing Writing, n. 8, p. 216-237, 2003.

LEFFA, V. J. A look at students' concept of language learning. Trabalhos em Lingüistica Aplicada, n. 17, p. 57-65, 1991.

LENNON, P. Error: some problems of definition, identification, and distinction. Applied linguistics, v. 12, p. 180-196, 1991.

LEWIS, M. The lexical approach: the state of ELT and a way forward. London: Commercial Colour Press, 1993.

LYRIO, A. L. L. Teachers' and students' expectations regarding the correction of oral errors in EFL. In: HAMMES, W. J.; VETROMILLE-CASTRO, R. (Org.). Transformando a sala de aula, transformando o mundo: ensino e pesquisa em língua estrangeira. Pelotas: EDUCAT, 2001. p. 233-267.

MATEUS, E. F.; GIMENEZ, T. N.; ORTENZI, D. I. B.G.; REIS, S. A prática do ensino de Inglês: desenvolvimento de competências ou legitimação das crenças? Um estudo de caso. Revista Brasileira de Lingüistica Aplicada, v. 2, n. 1, p. 43-59, 2002.

MUNBY, H. A qualitative approach to the study of a teacher's beliefs. Journal of Research in Science Teaching, v. 21, n. 1, p. 27-38, 1984.

NESPOR, J. The role of beliefs in the practice of teaching. Journal of Curriculum Studies, v. 19, n. 4, p. 317-328, 1987.

PAJARES, M. F. Teacher's beliefs and educational research: cleaning up a messy construct. Review of Educational Research, v. 62, n. 3, p. 307-332, 1992.

PINTRICH, P. R.; MARX, R. W.; BOYLE, R. A. Beyond a conceptual change: the role of motivational beliefs and classroom contextual factors in the process of conceptual change. Review of Educational Research, v. 63, n. 2, p. $167-199,1993$. 
RICHARDS, J. C.; LOCKHART, C. Reflective teaching in second language classrooms. Cambridge: Cambridge Language Education, 1996.

SCHULZ, R. A. Focus on form in the foreign language classroom: students' and teachers' views on error correction and role of grammar. Foreign Language Annals, v. 29, n. 3, p. 343-364, 1996.

SILVA, I. M. da. Percepções do que seja um bom professor de inglês para formandos de Letras: um estudo de caso. 2000. Dissertação (Mestrado em Letras) - Faculdade de Letras, Universidade Federal de Minas Gerais, Belo Horizonte, 2000.

WOODS, D. Teacher cognition in language teaching: beliefs, decisionmaking, and classroom practice. Cambridge: Cambridge University Press, 1996. 
$+1$ 